\title{
Parameter Identification
}

National Cancer Institute

\section{Source}

National Cancer Institute. Parameter Identification. NCI Thesaurus. Code C94945.

A process of finding model parameters that give a best fit of the model to the data points from a system. 